\title{
Clinical Pharmacy Services and Human Resources Requirements at MOH Primary Healthcare Centers during Ten years Mass Gathering Hajj (2006-2015) in Makah and Al-Medina Regions, Saudi Arabia
}

\author{
Yousef Ahmed Alomi*1, Khairat Alhennawi ${ }^{2}$, Nizar Khayayt ${ }^{3}$ \\ ${ }^{1}$ The Past General Manager of General Administration of Pharmaceutical Care and \\ Head, National Clinical pharmacy, and pharmacy practice and Pharmacy $R \& D$ Administration, \\ Ministry of Health, Riyadh, KSA \\ ${ }^{2}$ Clinical pharmacy staff, General Administration of Pharmaceutical Care, Ministry of Health, Riyadh, KSA \\ ${ }^{3}$ Medication Safety Officer General Administration of Pharmaceutical care, Makkah Region, \\ Ministry of Health, Riyadh, KSA
}

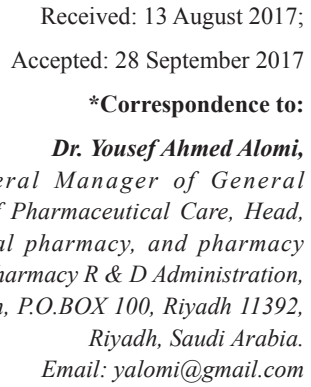

Copyright: (C) the author(s),publisher and licensee Indian Academy of Pharmacists. This is an openaccess article distributed under the terms of the Creative Commons Attribution Non-Commercial License, which permits unrestricted non-commercial use, distribution, and reproduction in any medium, provided the original work is properly cited.

\begin{abstract}
Objective: To explore the clinical pharmacy services and workforce requirements at Ministry of Health primary health care centers during mass gathering Hajj ten years (2006-2015) at Makah and Al-Medina Regions in Saudi Arabia. Methods: It is a retrospective analysis of ten years (2006-2015) of $\mathrm{MOH}$ primary health care centers (PCC) pharmacies during mass gathering Hajj period (15-30 days). The clinical pharmacist should provide pharmaceutical care to all patients either Pilgrim or not Pilgrim at Makah region. It included Mona holy places hospitals; Arafat holy places hospitals, and Makah city. The workforce requirements calculated based on $\mathrm{MOH}$ workforce standards of hospitals. The clinical activities drive from $\mathrm{MOH}$ critical care services, and emergency services, and mortality rate data. The nine clinical pharmacy services characterized by reduction mortality cost saving and mass gathering demand chosen. American College of Clinical Pharmacy (ACCP) model of clinical activities used. Results: The total number of Pilgrims was $(1,952,817-3,161,573)$ with average $(2,445,208)$. The average number of clinical pharmacists needed was (41.7 FTE) at holy places Primary Care Centers, while (94 FTE) at primary care centers in Makah city, and (16.6 FTE) at primary care centers at Al-Medina Region. The total number of clinical pharmacists needed per 10,000 population was (244.52 FTE) in Makkah region while (195.28 FTE) in Al-Madina region. Conclusion: There is a much demand of clinical pharmacist at primary care centers during mass gathering Hajj period in Makkah and Al-Madina regions. The clinical pharmacist in plays very vital role in public society especially chronic illness with emphasis mass gathering of reducing morbidity and mortality. In addition to preventing unnecessary additional cost. Key word: Clinical Pharmacy, Primary Care Center, Workload, Workforces, Mass Gathering, Hajj.
\end{abstract}

\section{INTRODUCTION}

In Islam, the Hajj considered the fifth pillar; it is a unique event that occurs every year and the result of the greatest mass gatherings in the world. It is more than 2 million people concentrate together to perform hajj rituals. It is conducted in Makah and holy places (Mina and Arafat), however; many pilgrims also visit Al-Medina during 
Hajj period. As with other mass gathering events, many health problems could occur during this time ranging from mild to serious health illnesses; and from communicable to non-communicable diseases. ${ }^{[1]}$ These diseases may include; infectious diseases, respiratory diseases, injuries, and uncontrolled chronic conditions like diabetes and hypertension. ${ }^{[2]}$ Those patients, although they are sick, usually prefer fast and easy to reach health care facilities, to spend their major time performing Hajj rituals. ${ }^{[3]}$ Because of that, paying attention to the primary health care centers, their facilities, and staffing, is a crucial aspect that should take into account. Because of that, some studies have focused on primary health care services; like the study which has been conducted in Mina holy places hospital to assess the workload in $1999 .{ }^{[4]}$ After pervasive literature review and only limited number of studies discussed utilized physician and nurses during mass gathering events but not pharmacists or clinical pharmacist at primary care centers. ${ }^{[5-7]}$ Pharmaceutical care is considered essential in such circumstances, in which health care centers will receive many patients with multiple health conditions, so clinical pharmacists will work to ensure - in a fast working environment- that patients are taking the best medication with the least side effects and drug interaction. ${ }^{[8]}$ It is important to note that, mass gathering pharmaceutical care during hajj and the assessment of pharmaceutical care program first studied in 2016. ${ }^{[8,9]}$ In our study, we focused on clinical pharmacists' services and workforce requirements, particularly in primary health care centers, during ten years period (2006 - 2015). The author not familiar with published studies discussed primary care center pharmacy workforces during mass gathering meeting or even during Hajj period in Saudi Arabia or Gulf countries and the Middle East countries also worldwide countries.

\section{METHODS}

It is a retrospective analysis of ten years (2006-2015) of $\mathrm{MOH}$ primary care center clinical pharmacists during mass gathering Hajj period (15 days) in Makkah region and nine years (2006-2014) of MOH primary care center clinical pharmacists during mass gathering Hajj period (15-30 days) in Al-Madina region. All data derived from Ministry of Health. Health Statistical Year Books. ${ }^{[10-19]}$ Primary healthcare is the essential healthcare and the first stage the patient face when he needs healthcare system. They manage patients with acute and chronic common illnesses and provide sufficient care for patients who do not need a hospital. The patients who need an advanced level of care referred to hospitals. National Primary care Pharmacy Competency contained; primary care pharmacist and clinical pharmacist, pharmacy administration, and different specialization clinical pharmacists. ${ }^{[20]}$ The clinical pharmacist should provide pharmaceutical to all patients either Pilgrim or not Pilgrim at Makah and Al-Medina regions. Makah region includes Mina holy places PCC; Arafat holy places PCC, and Makah city. There are about 158 Primary care centers in Makah region (46 centers in Makah city and 112 centers in the holy places). ${ }^{[19]}$ Examples of competencies of clinical pharmacy in primary care centers include; general medicine competency and psychiatry competency. The family medicine competency, general pediatrics competency, and other specific specializations. ${ }^{[20]}$ They educate the patient about his medication and monitor his drug therapy. Also, there was extensive literature review search at open date periods with fifty databases. The Current Content via Web of Knowledge, Dentistry and Oral Science via EBSCO, Clinical Key -Nursing, Clinical Key- Physician, CINAHL via EBSCO, Central via ProQuest, CBCA via ProQuest, Canadian Science Publishing.Cambridge Journals via Cambridge University, Britannica Academic, BMJ Journals, BMJ Clinical Evidence via BMJ Best Practice, BMJ Best Practice, Biology Journals via ProQuest, ACM Digital Library, Academic Search Ultimate via EBSCO, Cochrane Library Pubmed, and Google Scholar. It included the type of studies (meta-analysis, randomized controlled studies, and observational studies, books, reports, etc.) in the English language. The search for the term of Hajj and workforce, Hajj and workforce, Hajj and human resources or mass gathering and workforce, mass gathering and workforce, mass gathering and human resources. The search term was in the title and keywords. All setting of patient care services; hospitals inpatient or ambulatory care or community services included. The search included pharmacist and clinical pharmacist. Pharmacy technician excluded from the study. The location of studies included Saudi Arabia as top propriety if not existed Gulf or Middle East countries included, if not found overall countries included. The workforce requirements calculated based on $\mathrm{MOH}$ workforce standards of hospitals. ${ }^{[21]}$ The clinical activities drive from $\mathrm{MOH}$ critical care services, emergency services, and mortality rate data. The nine clinical pharmacy services characterized by reduction mortality cost-saving and mass gathering demand chosen. American College of Clinical Pharmacy (ACCP) model of clinical activities used. The central pharmacy activities including drug information, drug utilization evaluation, pharmacoeconomics, while patient-centered clinical activity including internal medicine services, cardiology services, infectious disease, and pediatrics services. Administrative pharmacy activities including medication safety, pharmacy research. ${ }^{[22-24]}$ Also, 
additional clinical pharmacy services or program impeded or supportive with first services for instant pharmacy Anticoagulation program, pharmacy pain management program, pharmacy infection control, medication therapy management. The pharmacy technician and nonclinical pharmacist workforce excluded in the calculations. All calculation done used Microsoft Excel version ten.

\section{RESULTS}

The total number of Pilgrims was $(1,952,817-3,161,573)$ with average $(2,445,208)$. In Makah Region; The total number of prescriptions at PCC $(226,824-505,753)$ with average $(411,317)$, it represented $(7.12-20.25 \%)$ with average (16.77\%) of all pilgrims. In Al-Medina Region; the total number of Pilgrims was $(1,952,817-3,161,573)$ with average of $(2,445,208)$. The total number of prescriptions at PCC was $(35,149-207,444)$ with an average $(142,080)$. It represented $(1.48-8.35 \%)$ with an average $(5.79 \%)$ of all pilgrims. The total number of primary care centers in Makkah region was (135.7) center and in Makkah city was (36 - 46) centers with an average of (41.7), while in holy places there was $(80-112)$ with an average of (94) Primary Care Centers. In Al-Medina, there was $(7-19)$ with average of (16.6) primary care centers. The average number of clinical pharmacists needed was (41.7 FTE) at holy places Primary Care Centers, while (94 FTE) at primary care centers in Makah city, and (16.6 FTE) at primary care centers at Al-Medina Region. The total number of clinical pharmacists needed per 10,000 population was (244.52 FTE) in Makkah region while (195.28 FTE) in Al-Madina region. The number of clinical pharmacists based on population calculation as compared with $\mathrm{MOH}$ standards almost double in Makkah region while incremental eleventime fold in Al-Madina region as explored in Table 1 and Table 2. The number pharmacist is limited to apply ACCP standards in Makkah while in Al-Madina region with the central pharmacy activities needed was (3 FTE), patient-centered clinical activity was (4 FTE) while the administrative pharmacy activities (2 FTE). Also additional clinical pharmacy services or program needed (2.76 FTE).

\section{DISCUSSION}

The general administration of Pharmaceutical Care started the clinical pharmacy services in $2014 .{ }^{[25]}$ That s need change pharmacy primary care center skeleton administration, updated the pharmacy workforces. Moreover, implemented the competency of various clinical pharmacy specialties at primary health centers. ${ }^{[20-21]}$ Those changes cover all pharmacy primary care centers over all king of

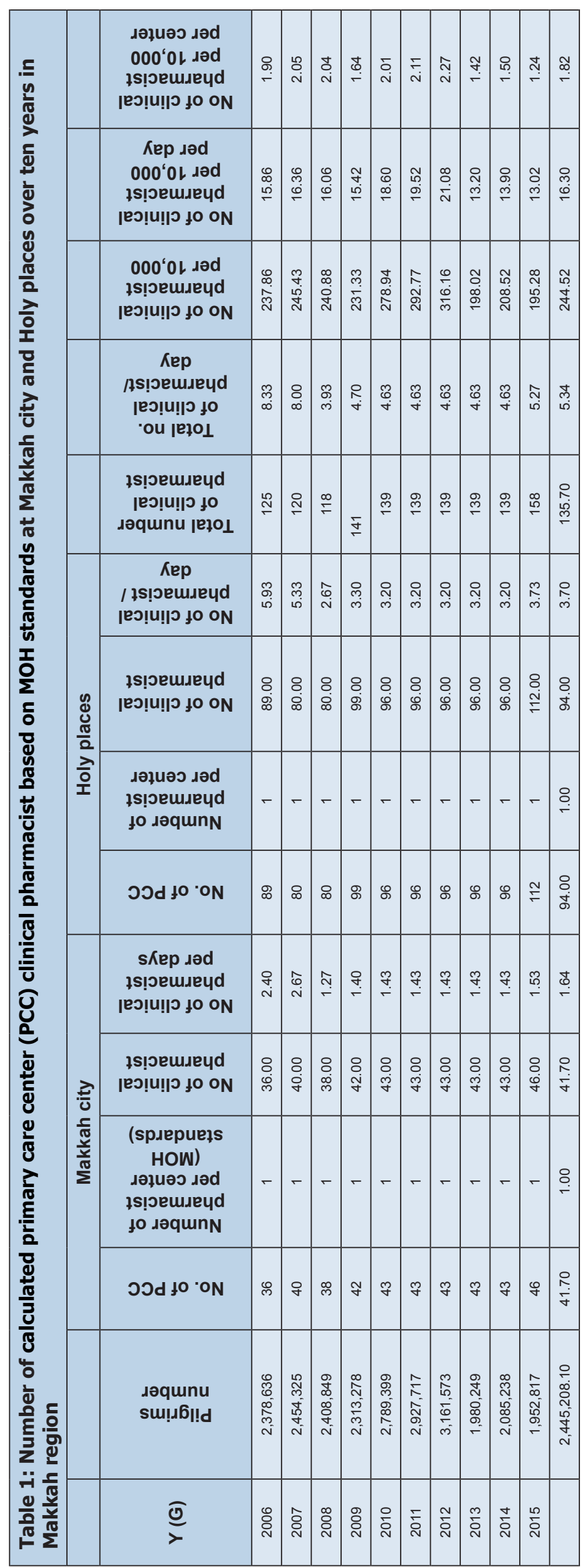




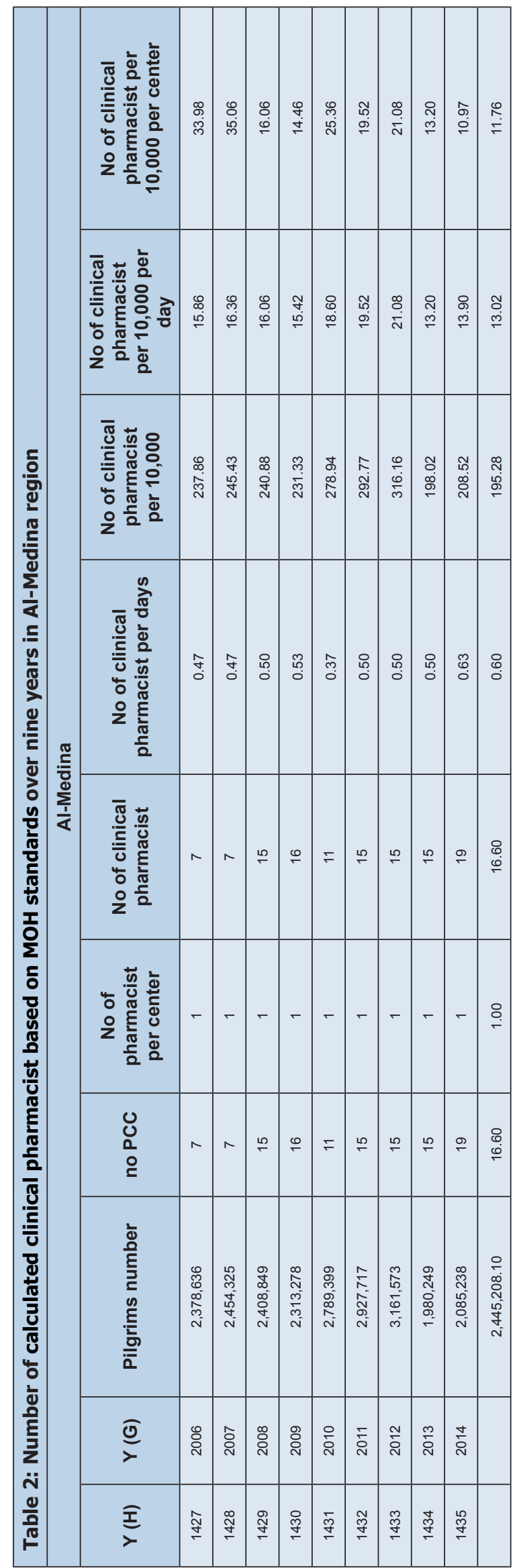

Saudi Arabia including Makkah city, holy places, and Al-Madina region. The implementation according to the new strategic plan of medical services 2010-2020. ${ }^{[2]}$ The authors tried to examine the clinical pharmacy services and pharmacy workforce in primary care centers in 10 years during hajj. The results reflect the high demand for clinical pharmacists during mass gathering events like hajj. The number of clinical pharmacists needed to calculated according to $\mathrm{MOH}$ standards in Saudi Arabia. There was a study also conducted in Saudi Arabia in 2014, and it assesses the demand for pharmacists and clinical pharmacists in primary healthcare centers. ${ }^{[20]}$ Another study published in Jan 2017 about health workforce planning suggested that a population of 10,000 people needs one pharmacist. ${ }^{[27]}$ However, these studies done in normal environments, not in mass gathering events, so we have calculated the Full-Time Employees needed according to the number of prescriptions during these years and clinical pharmacist not calculated. Unfortunately, there are insufficient studies to compare with it. It is the first study to calculate clinical pharmacy services workforce for mass gathering event. The authors tried to the calculated number of clinical pharmacy during mass gathering hajj time by using new $\mathrm{MOH}$ pharmacy workforces of primary care centers and population-based calculation. The highest number of clinical pharmacists needed was in Makah followed by holy places, and the least number was in Al-Medina. The results expected, as not all pilgrims visit Al-Medina during hajj, and there are no rituals there, which need extensive efforts. The number of primary care centers in Makah and holy places also more than that in Al-Medina. However, the number of clinical pharmacist per primary care center based on population the results showed the very higher demand of Al-Madina region than Makkah region that's due to the low number of primary care centers in Al-Madina and a significant number in Makk with same almost same number of pilgrims. Those figures of clinical pharmacists needed show the paramount importance of planning before Hajj and knowing the exact number of clinical pharmacists needed with different specialties. The authors excluded the pharmacy technician and pharmacy for further studies in the future.

Limitation: Although the study showed the crucial information of clinical pharmacy services at primary care centers. With an emphasis on mass gathering Hajj time. It contained certain restrictions out of author control. For instance, the number of clinical pharmacists not reported in $\mathrm{MOH}$ statistical books, the official documentation pharmacist intervention through pharmacy administration missing data of drug information inquiries answers and cost avoidance of impact clinical pharmacy services at primary care centers. 


\section{CONCLUSION}

The pharmacist workforce during a mass gathering of Hajj time is very potential. The demand clinical pharmacist workforce at primary care centers several times incremental than $\mathrm{MOH}$ standards or population based calculations during mass gathering Hajj period. The clinical pharmacist is critical to preventing drug related problems for pilgrims, drug misadventures, and improves patient clinical outcomes during mass gathering events.

\section{ACKNOWLEDGEMENT}

I want to thank all staff at Health affairs administration and pharmaceutical care administration in Makkah and Al-Madina regions for their cooperation.

\section{CONFLICT OF INTEREST}

None

\section{ABBREVIATION USED}

KSA: Kingdom of Saudi Arabia, MOH: Ministry of Health, PCC: Primary care center

\section{REFERENCES}

1. Memish ZA. The Hajj: communicable and non-communicable health hazards and current guidance for pilgrims. Euro surveillance. 2010;15(39):19671.

2. Khan NA, Ishag AM, Ahmad MS, El-Sayed FM, Bachal ZA, Abbas TG. Pattern of medical diseases and determinants of prognosis of hospitalization during 2005 Muslim pilgrimage (Hajj) in a tertiary care hospital. A prospective cohort studies. Saudi Med J. 2006;27(9):1373-80.

3. Shakir HAS, Gazzaz ZJ, Dhaffar KO, Shahbaz J. Outpatient Services during (1423h) Hajj Season. Sultan Qaboos University Med J. 2006;6(1):47-50.

4. Alomi YA. Mass Gathering Pharmaceutical Care Handbook. General Administration of Pharmaceutical Care, Ministry of Health; 2015.

5. Centre for Excellence in Emergency Preparedness $\odot$ An Introduction to Mass Gatherings Introduction to Mass Gatherings. 2014; Available from http://www.ceep.ca/publications/Mass_Gatherings.pdf.

6. Sanders Ab, Criss E, Stecki P, Meislin HWH, Raife J, Allen, et al. An analysis of medical care at mass gatherings. Ann Emergency Med. 1986;15(5):515-9.

7. Smith WP, Wessels V, Naicker D, Leuenberger E, Fuhri P, Wallis LA, et al.
Development of a mass-gathering medical resource matrix for a developing world scenario. Prehospital Disaster Med. 2010;25(6):547-52.

8. Ahmed-Alomi Y, Pharm B, Clin-Pharm M. National Mass Gathering Pharmaceutical Care Program at $\mathrm{MOH}$ in Saudi Arabia. J Pharm Practice Community Med. 2016;2(23):102-3.

9. Alomi YA, Zahran R. Self-Assessment of mass gathering (Hajj) pharmaceutical care program in Saudi Arabia. J Pharm Practice Community Med. 2016;2(24):137-43.

10. Saudi Ministry of Health. Health Statistical Year Book 2006. Available from http://www.moh.gov.sa/en/Ministry/Statistics/book/flash/1427/ MOH_Report_1427.html.

11. Saudi Ministry of Health. Health Statistical Year Book 2007. Available from http://www.moh.gov.sa/en/Ministry/Statistics/book/flash/1428/ MOH_Report_1428.html.

12. Saudi Ministry of Health. Health Statistical Year Book 2008. Available from: http://www.moh.gov.sa/en/Ministry/Statistics/book/flash/1429/ MOH_Report_1429.html.

13. Saudi Ministry of Health. Health Statistical Year Book 2009. Available from http://www.moh.gov.sa/en/Ministry/Statistics/book/flash/1430/ MOH_Report_1430.html.

14. Saudi Ministry of Health. Health Statistical Year Book 2010; Available from http://www.moh.gov.sa/en/Ministry/Statistics/book/Pages/default.aspx.

15. Saudi Ministry of Health. Health Statistical Year Book 2011; Available from http://www.moh.gov.sa/en/Ministry/Statistics/book/Pages/default.aspx.

16. Health Statistical Year Book 2012. Saudi Ministry of Health. Available from: http://www.moh.gov.sa/Ministry/Statistics/book/Documents/1433.pdf.

17. Saudi Ministry of Health. Health Statistical Year Book 2013. Available from: http://www.moh.gov.sa/en/Ministry/Statistics/book/Pages/default.aspx.

18. Saudi Ministry of Health. Health Statistical Year Book 2014. Available from: http://www.moh.gov.sa/en/Ministry/Statistics/book/Documents/StatisticalBook-for-the-Year-1435.pdf.

19. Saudi Ministry of Health. Health Statistical Year Book 2015. Saudi Ministry of Health. Available from: http://www.moh.gov.sa/ministry/statistics/book/ pages/default.aspx.

20. Alomi YA. National Primary Care Pharmacist Competency System at MOH in Saudi Arabia. J Pharm Pharm Sci. 2017;1(14):1-5.

21. Alomi YA. Primary Care Center Pharmacy Manpower New Guidelines in Saudi Arabia. J Pharmacology Clinical Res. 2016;1(1).

22. Bond CA, Raehl CL, Franke T. Clinical pharmacy services and hospital mortality rates. Pharmacotherapy. 1999;19(5):556-64.

23. Bond C, Raehl C, Franke T. Total Cost of Care, and Length of Stay in United States Pharmacy Services and Staffing. Pharmacotherapy. 2001;21(2):129-41.

24. Bond CA, Raehl CL. Clinical pharmacy services, pharmacy staffing, and hospital mortality rates. Pharmacotherapy. 2007;27(4):481-93.

25. Alomi YA. National Pharmacy Practice Programs at Ministry of Health in Saudi Arabia. J Pharm Pharm Sci. 2015;1(2):17-8.

26. Alomi YA, Alghamdi SJ, Alattyh RA. Strategic Plan of General Administration of Pharmaceutical Care at Ministry of Health in Saudi Arabia 2012-2022. J Pharm Pharm Sci. 2015;1(3):1-8.

27. Bloom BS. Health manpower planning. Health Service Res. 1980;15(1):67-8.

Cite this article as: Alomi YA, Alhennawi K, Khayayt N. Clinical Pharmacy Services And Human Resources Requirements At MOH Primary Healthcare Centers During Ten Years Mass Gathering Hajj (2006-2015) In Makah And Al-Medina Regions, Saudi Arabia. J Pharm Pract Community Med. 2017;3(4s):S43-S47. 